\title{
A importância da reciclagem nas indústrias têxteis: $o$ caso da indústria Martex Fiber
}

\author{
The importance of recycling in textile industries: the case of the Martex Fiber industry
}

Recebido: 20/10/2021 | Revisado: 25/10/2021 | Aceito: 27/10/2021 | Publicado: 31/10/2021

\author{
Ildo Barbosa Alves \\ ORCID: https://orcid.org/0000-0002-4087-9887 \\ Universidade Federal de Campina Grande, Brasil \\ E-mail: Ildo.2011.barbosa@gmail.com \\ Isabel Lausanne Fontgalland \\ ORCID: https://orcid.org/0000-0002-0087-2840 \\ Universidade Federal de Campina Grande, Brasil \\ E-mail: isabelfontgalland@gmail.com
}

\begin{abstract}
Resumo
A Martex Fiber tem inovado no campo da reciclagem de têxteis desde a sua fundação em 1970 como uma empresa de comercialização de resíduos têxteis, ela cresceu e se tornou líder no processo de gerenciamento de resíduos têxteis na América do Norte e Central e no Caribe. Acredita que os resíduos têxteis não devem ser colocados em aterros porque a reciclagem é boa para as indústrias, possui uma sofisticada logística de transporte, tudo que possa possibilitar através do gerenciamento a produzir mais com a menor quantia de gastos possível, além de ofertar matéria primas recicladas a diversos segmentos industrias. O presente trabalho se caracteriza como um estudo de caso e, como objetivo busca abordar a dinâmica da reciclagem, apresentar os resultados e, por fim as considerações finais.
\end{abstract}

Palavras-chave: Indústrias têxteis; Reciclagem; Martex Fiber.

\begin{abstract}
Martex Fiber has been innovating in the field of textile recycling since it's founding in 1970 as a textile waste trading company, it has grown to become a leader in the textile waste management process in North and Central America and the Caribbean. It believes that textile waste should not be placed in landfills because recycling is good for industries, it has a sophisticated transport logistics, everything that can make it possible, through the management, to produce more with the least amount of expenses possible, in addition to supplying raw materials recycled to various industrial segments. The present study is characterized as a case study and, as its objective, it seeks to approach the dynamics of recycling, to present the results and, finally, the final considerations.
\end{abstract}

Keywords: Textile industries; Recycling; Martex Fiber.

\section{Introdução}

Ao se tratar de problemas relacionados as atividades industriais, há uma política de interesse coletivo em prol de um meio ambiente sustentável e neste sentido, as indústrias são direcionadas a reaproveitar o máximo possível dos resíduos, e isso contribui com as questões ambientais e ao mesmo tempo coma maximização das receitas.

Os resíduos industriais são sobras, dejetos ou restos advindos das atividades fabris, são encontrados em todos os estados físico da matéria, sendo que existem aqueles que são recicláveis ou reaproveitados. Sua composição depende dos tipos de processos industriais pelos quais passou e a reciclagem é neste sentido segundo Leite, afirma:

"Área da logística empresarial que planeja, opera e controla o fluxo e as informações correspondentes, do retorno dos bens de pós-venda e de pós-consumo ao ciclo de negócios ou ao ciclo produtivo, por meio dos canais de distribuição reversos, agregando-lhes valor de diversas naturezas: econômico, legal, de imagem corporativa, entre outros"(LEITE, 2003).

Neste sentido surgem diversas empresas a colaborar com os serviços pós consumo, muitas vezes de uma logística e exclusividade especifica que acaba se consolidando no mercado e minunciosamente dando um destino aos resíduos, fazendo 
uma parceria que se torna lucrativa para ambas as partes, é o caso da Martex Fiber por ser a principal recicladora de têxteis da América do Norte. Essa empresa tem como lema, "zero aterro, nenhuma fibra deixada para trás".

A equipe da Martex Fiber acredita que os resíduos têxteis não devem ser colocados em aterros porque a reciclagem é boa para as indústrias, o meio ambiente e a sociedade, reduz os riscos para o meio ambiente ocasionando redução nos gastos de recursos naturais na produção de novas fibras sintética.

O presente trabalho analisará se a Martex Fiber dispõe de um gerenciamento capaz de beneficiar as indústrias têxteis. A indústria que compra resíduos a outa, tem-se um benefício mutuo.

Devido as indústrias têxteis serem potencialmente poluidoras para o meio ambiente e as indústrias de reciclagem se apresentar em busca de parcerias, será importante um estudo sobre Martex Fiber.

\section{Metodologia}

De acordo com Lakatos e Marconi (2007) a pesquisa requer uma metodologia formal com um tratamento científico para que se tenha uma ligação e possa, conhecer a realidade e as verdades parciais.

Neste caso, a pesquisa será classificada como um estudo de caso, caracterizada com uma metodologia investigativa de caráter empírico para averiguar a situação real acerca da dinâmica desempenhada pela empresa recicladora em parceria com as indústrias têxteis e segundo Miguel (2010) o estudo de caso está ligado a literatura para atender os objetivos propostos com a finalidade de contribuir com os resultados.

\section{Resultados e Discussão}

A Martex Fiber tem inovado no campo da reciclagem de têxteis desde a sua fundação em 1970 como uma empresa de comercialização de resíduos têxteis. A empresa também recicla mecanicamente algodão-poliéster e outras matérias.

\subsection{Crescimento e consolidação da Empresa}

A empresa cresceu e se tornou líder no processo de gerenciamento de resíduos têxteis, passando a oferecer serviços de alta qualidade para uma ampla variedade de fábricas têxteis na América do Norte e Central e no Caribe. Essa escolha estratégica desse referido setor industrial para atuação foi importante, visto que, diversas indústrias têxteis podem apresentar dificuldade e desmotivação devido ao custo no gerenciamento dos resíduos, mas a vantagem de reciclar é evidente e segundo:

\footnotetext{
"No caso das indústrias de confecção, que compram tecidos para a fabricação de produtos, os resíduos reciclados podem ser amplamente utilizados não só no setor têxtil: seja para formarem-se novos fios e estes transformarem-se em novos tecidos ou para o uso em outros ramos da indústria, a reciclagem de tecidos é um importante aliado na geração de emprego e renda". (PENSAMENTO VERDE, 2013).
}

O crescimento e consolidação da empresa estudada, nesse ramo de atuação foi prospero e logo se consolidou no mercado, visto que, as indústrias têxteis são potencialmente poluidoras e causadoras de efeitos negativos ao meio ambiente, por um lado elas precisam atender as legislações ambientais e por outro querem a maximização da receita, bem como a preocupação de passar uma boa imagem para a sociedade, indo no mesmo sentido que Elsevier, (2013) que afirma. "A propaganda é um instrumento muito utilizado para a diferenciação de produtos".

\subsection{Processos de Reciclagem da Empresa}

A empresa dispões de um esquema de reciclagem onde todas as etapas dos processos são minunciosamente 
observadas, desde o corte e classificação das sobras e tipos tecidos, o que possibilita uma boa recuperação, após o aproveitamento dessa matéria prima, novo ciclo industrial de reciclagem será repetido, se observa na Figura 1, a seguir, ao mostra o processo de reciclagem seguido pela empresa:

Figura 1: The Martex Fiber $360^{\circ}$ Recycling Process.

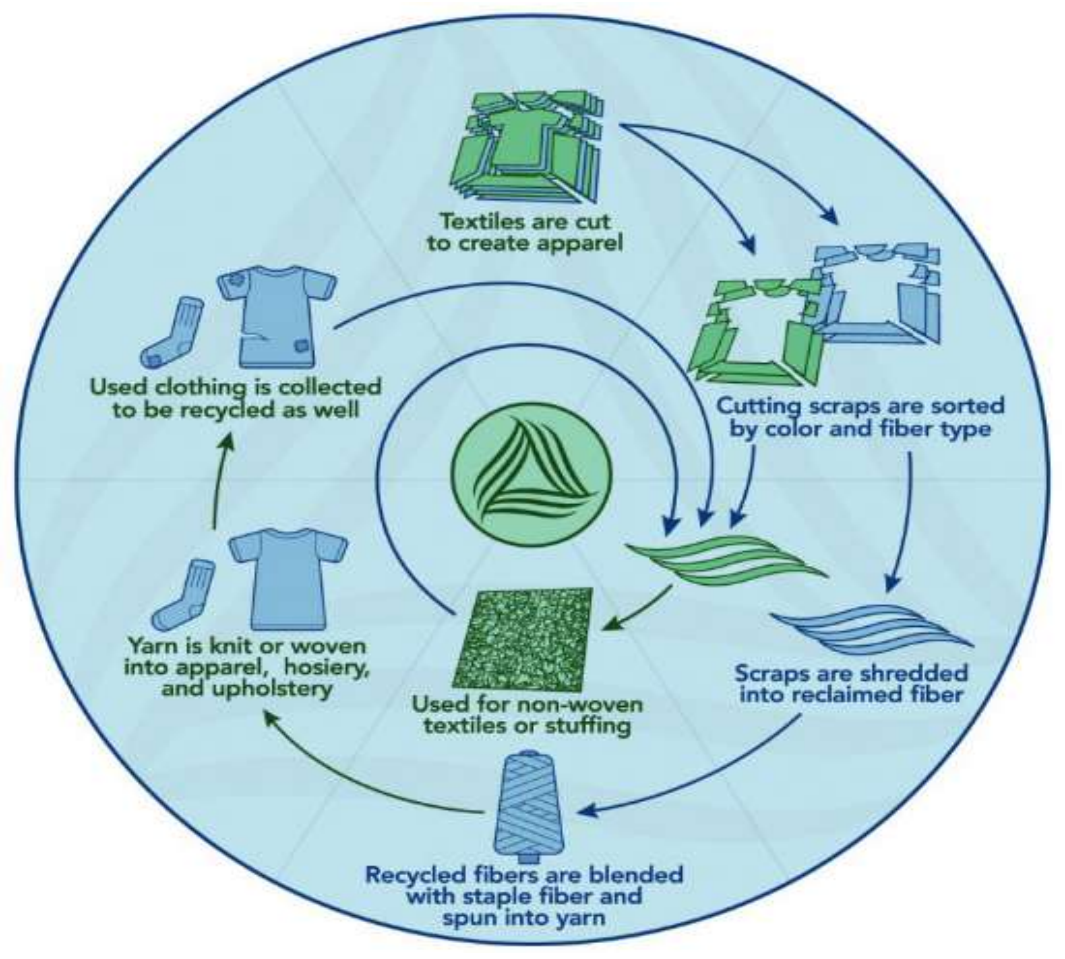

Fonte: Martex Fiber.

\subsection{Parceiro Perfeito da Industria Têxtil}

A Martex Faber é uma empresa de reciclagem de alta capacidade de gerenciamento de resíduos industrias e, no que diz respeito ao setor têxtil a empresa dispões de mais de 40 anos de experiência. Desenvolve trabalhos elaborando plano de gerenciamento dos resíduos de acordo com as necessidades das industrias parceiras e se responsabilizar pela referida demanda perante a indústria têxtil.

Ao usar a Martex Fiber para seus serviços de resíduos, a indústria têxtil tem a certeza de que os resíduos serão coletados quando necessário, concentrando-se em seus negócios em vez de nos resíduos, segunda afirma:

"Sob este ponto de vista, parcerias com empresas de reciclagem e destinação final de resíduos são imprescindíveis, pois retiram da organização geradora a responsabilidade de realizar todo o processo e permite que ela foque mais em seu negócio principal, aumentando assim a lucratividade”. (VGR, 2013)

Além disso, ao reciclar com a Martex Fiber a indústria têxtil terá um gerenciamento dos resíduos organizado possibilitando a maximização de receitas através do aproveitamento deles.

A Martex Fiber possui uma sofisticada logística, com caminhões, container, reboques, tudo isso possibilita no gerenciamento a produzir mais com a menor quantia de gastos possível, conforme se observa na Figura 2 a seguir: 
Figura 2: Cutting Operations.

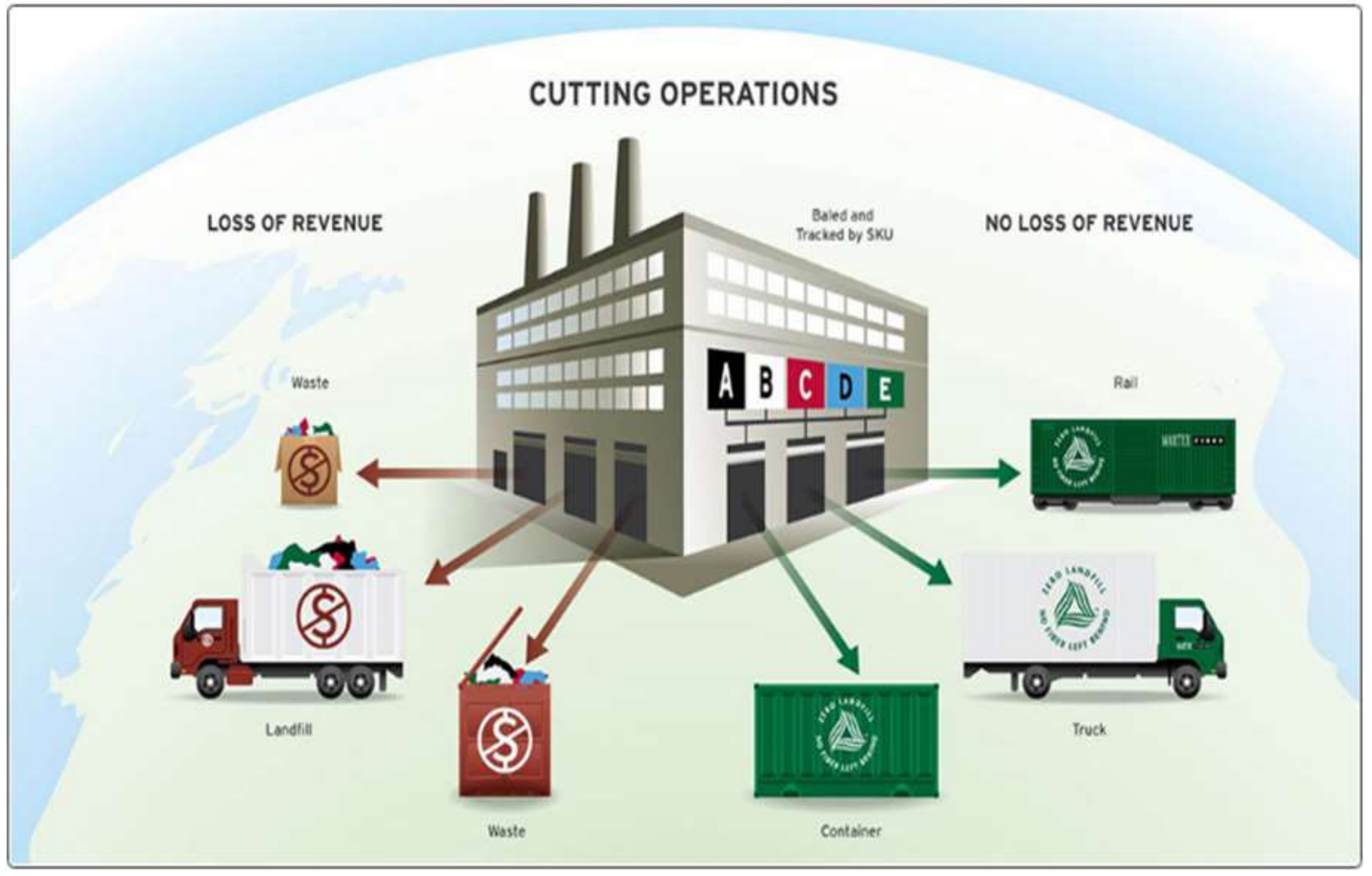

Fonte: Martex Fiber.

Pode-se perceber a importância da logística gerenciada pela empresa recicladora, ao gerar ganhos no processo de reciclagem, tornado ambas as partes lucrativas e causando o menor impacto possível ao meio ambiente.

\subsection{Produtos da Empresa}

A Materx Fiber consegue uma vasta quantidade de matéria prima para reciclagem, o que faz ser uma fornecedora de matéria prima reciclada para uma variedade de indústria, tendo como matéria prima: cortes de para-aramidas, teias, panos de limpeza, rolos de têxteis em diversos tamanho, resíduos de linha em mistura de algodão, esses materiais são imprescindível, pois são reciclados, novamente entra no processo produtivo, causando uma situação econômica e sustentável em todos os aspectos, visto que os recursos naturais são escassos e o aproveitamento desses materiais para o processamento industrial como no caso que será mostrado na Figura 3, da fibra usinada recuperada serve para uma variedade de aplicações sopro e enchimento, incluindo travesseiros, apoios de cama e equipamentos esportivos: 
Figura 3: Cutting Operations.

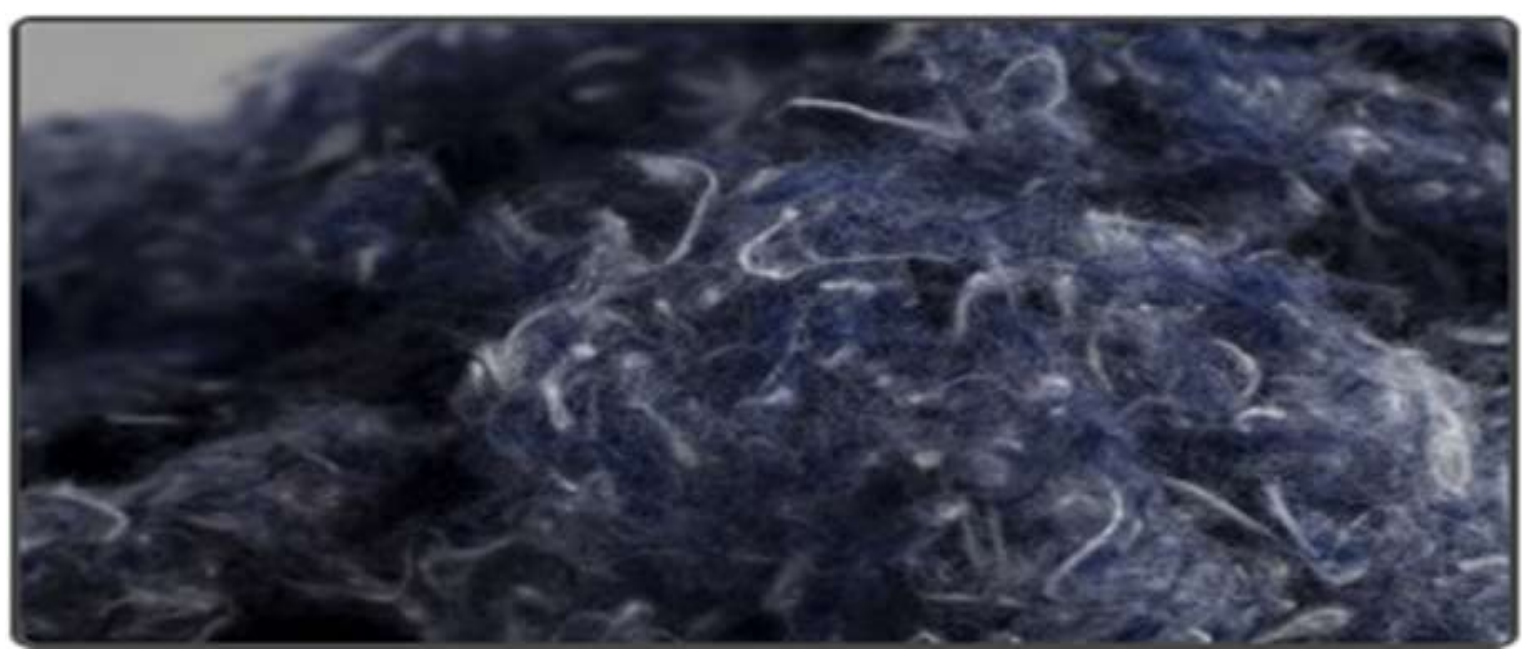

Fonte: Martex Fiber.

O gerenciamento dos resíduos pela Martex Fiber possibilita o reaproveitamento correto e a inserção de matérias primas recicladas em novos processos industriais conforme mostrado na figura acima, matérias primas advindas da reciclagem prontas para entrar num novo circo produtivo. Observa-se na Quadro 1, as principais matérias primas transformadas e respectivos setores industriais que que a Martex Fiber é fornecedora.

\section{Quadro 1:}

\begin{tabular}{|l|l|}
\hline Materiais Reciclados & Aproveitamento Industrial \\
\hline Papelão & Indústria de Papel \\
\hline Metal & Indústria de Metal \\
\hline Tecidos & Indústria de Têxteis \\
\hline Fibras Usinadas & Indústria de Móveis \\
\hline
\end{tabular}

Fonte: Elaboração Própria.

A Maxtex Fiber é considerada uma indústria, segundo o Infor Escola, "A indústria tem a finalidade de transformar matérias primas em vários tipos de produtos". A Martex Fiber também faz o reaproveitamento de resíduos não têxteis e de acordo com o Só Biologia, o metal "é um dos produtos mais utilizados nas tarefas do dia-a-dia."

\subsection{A importância da indústria Têxtil}

Devido ao momento de resseção econômica e crise na saúde pública mundial, todos os setores industriais enfrenta dificuldades na produção e comercialização, o índice de confiança do empresário industrial apresentou queda no mês de setembro de 2021 para todos os setores conforme mostra se observa na Tabela 1 
Tabela 1:

\begin{tabular}{ll} 
& 63,2 \\
\hline & 61,0 \\
\hline
\end{tabular}

Fonte: CNI Portal da Indústria.

Apesar da queda, todos os setores da Indústria ainda seguem com índices de confiança acima da linha divisória de 50 pontos, indicando que os empresários dos diferentes setores seguem confiantes. Contudo, a confiança se tornou mais fraca e menos disseminada que em agosto.

A situação de competitividade do Brasil entre 18 economia selecionadas não apresenta um bom destaque, conforme a Tabela 2 a seguir:

Tabela 2:

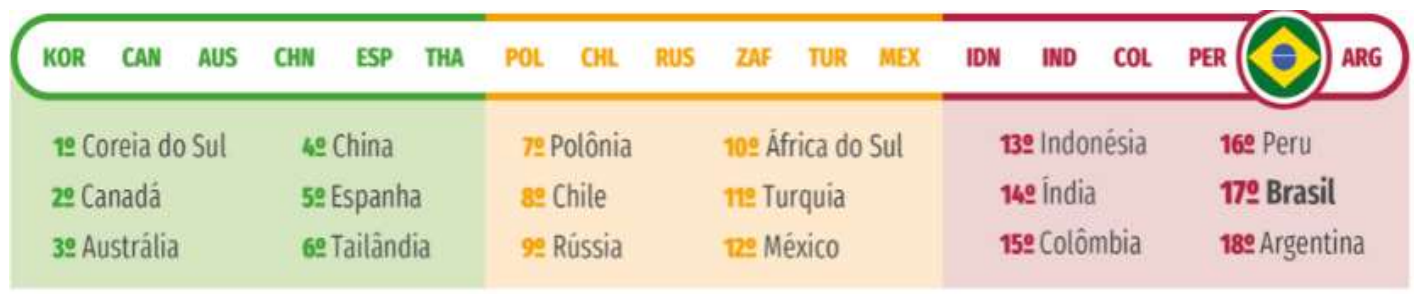

Fonte: CNI Portal da Indústria.

O resultado não tira país do penúltimo lugar, O Brasil é o penúltimo colocado no ranking. O Chile e o México, outros dois casos de países latino-americanos, ocupam a $8^{\mathrm{a}}$ e $12^{\mathrm{a}}$ posição, respectivamente. A Coreia do Sul é a economia mais competitiva.

Com relação a reciclagem mundial de acordo com o Ecomondo, a Irlanda é o país, mundialmente em destaque, “Desde o final dos anos 1990, as taxas de reciclagem têm aumentado drasticamente devido aos esforços da população".

\section{Conclusão}

Concluímos que a Martex Fiber por ser uma indústria de reciclagem do segmento têxtil, o qual é um dos ramos industriais que mais prejudica ao meio ambiente torna uma indústria imprescindível, e isso se evidencia principalmente ao fazer o elo econômico entre as indústrias têxteis maximizando suas receitas e outras ao adquirir matérias primas ofertadas por ela, advinda dos processos de reciclagem, além de promover o equilíbrio ambiental.

Outra importância que se materializa com a oferta de matéria primas recicladas para diversos segmentos industriais, evitando escassez com a exploração é o fato de possibilitar o menor desperdício possível no processo produtivo.

Ressalta-se a importância do estudo aqui em questão, pelo fato da temática está diretamente ligada a questões 
ambientes e o processo industrial ser imprescindível para a vida humana, sugere-se novos estudos acerca do caso para que o equilíbrio ambiental sempre seja alcançado.

\section{Referências}

Economia industrial: fundamentos teóricos e práticas no Brasil / organizadores, David Kupfer e Lia Hasenclever. (2a.ed.) Elsevier, 2013.

Ecomondo. (2021). Sustentabilidade. Website Ecomondo. Sustentabilidade. https://ecomondobrasil.com.br/sustentabilidade-irlanda-lidera-ranking-como-paisque-mais-recicla-roupas/

CNI (2021a). Estatísticas. Website CNI. http://www.portaldaindustria.com.br/estatisticas/icei-setorial/

CNI (2021b). Competitividade. Website CNI. http://www.portaldaindustria.com.br/estatisticas/competitividade-brasil-comparacao-com-paises-selecionados/ Infor escola (2021). Industrias. Website. https://www.infoescola.com/geografia/industrias/

Lakatos, E. M; \& Marconi, M. A. (2003) Fundamentos de metodologia científica. (5a.ed.). Atlas 312p.

Leite. (2003) Logística reversa meio ambiente e competitividade. São Paulo, Prentice Hall.

Martex Fiber (2021a). Cerca de. Website. http://www.martexfiber.com/about/

Martex Fiber (2021b). Cerca de. Website. http://www.martexfiber.com/waste-services/

Martex Fiber (2021c). Nossas Promessas. Website. http://www.martexfiber.com/our-pledges/

Martex Fiber (2021d). Produtos. Website. http://www.martexfiber.com/products/reclaimed-fiber/

Martex Fiber (2021e). Texteis Reciclados. Website. http://www.martexfiber.com/products/recycled-textiles/\#recycled-textiles

Paulo Augusto Cauchick. (2010) Metodologia de Pesquisa em Engenharia de Produção e Gestão de Operações. Rio de Janeiro: Elsevier.

Só BIologia (2021). Reciclagem dos Metais. Website. https://www.sobiologia.com.br/conteudos/reciclagem/reciclagem6.php

Pensamento Verde (2021). O processo de reciclagem de tecidos. Website. https://www.pensamentoverde.com.br/reciclagem/o-processo-de-reciclagem-detecidos/. Acessado em: 05/10/2021.

VGR (2021) Foque no que sua empresa faz de melhor. Website. https://www.vgresiduos.com.br/blog/a-importancia-das-parcerias-para-a-gestao-de-residuos/. Acessado em: 05/10/2021. 